\title{
Agronomic
}

Journal

\section{DESENVOLVIMENTO E PRODUTIVIDADE DO MILHO SUBMETIDO AO PARCELAMENTO DO NITROGÊNIO EM COBERTURA}

\author{
DEVELOPMENT AND PRODUCTIVITY OF MAIZE SUBMITTED TO THE NITROGEN INSTALLMENT IN \\ COVERAGE
}

Daniella Figueredo Fabrini' ${ }^{1}$; Maria Claudya Pereira Silva ${ }^{1}$; Cláudia Fabiana Alves Rezende ${ }^{2}$

${ }^{1}$ Discente do curso de Agronomia, UniEvangélica, Anápolis, GO, Brasil.

${ }^{2}$ Docente, Doutora em Agronomia, UniEvangélica, Anápolis, GO, Brasil.

\begin{tabular}{l} 
Info \\
\hline Recebido: 01/2021 \\
Publicado: 03/2021 \\
ISSN: 2595-6906 \\
DOI: 10.37951/2595-6906.2021v5i1.6524 \\
\hline Palavras-Chave \\
Nutrição de plantas; Zea Mays; \\
fertilizante nitrogenado. \\
Keywords: \\
Plant nutrition; Zea Mays; nitrogen \\
fertilizer.
\end{tabular}

\begin{abstract}
Resumo
O objetivo com esse trabalho foi verificar os resultados do parcelamento da adubação nitrogenada com ureia na cultura do milho grão no estágio V4 e V8. O experimento foi realizado na fazenda Ponte Alta, no município de Silvânia-GO. O delineamento experimental adotado foi o de blocos ao acaso, com quatro tratamentos e quatro repetições sendo: T1 Testemunha; T2 - Ureia 100\% V4; T3 - Ureia 50\% V4 e 50\% V8; T4 - Ureia $100 \%$ V8. A demanda nutricional da cultura foi estabelecido de acordo com a análise do solo sendo de $261 \mathrm{~kg}$ ha $^{-1}$ de N. Foram avaliados a altura da planta, diâmetro de colmo, massa verde e a altura da inserção da espiga até o florescimento pleno e a produtividade no final do
\end{abstract} experimento. Os resultados foram submetidos à análise de variância, e quando ocorreram diferenças significativas, identificadas pelo teste $\mathrm{F}(\mathrm{P}<0,05)$, se aplicou o teste de médias de Tukey, utilizando-se programa estatístico Sisvar, versão 5.6. O milho FS 2B610 PW respondeu positivamente à adubação nitrogenada de cobertura, em todas as características estudadas. Nas condições de solo e clima da área analisada, a adubação de cobertura nitrogenada para o desenvolvimento do milho é mais eficiente quanto a aplicação do $\mathrm{N}$ em cobertura é realizada no estádio vegetativo $\mathrm{V} 4$, se assemelhando produtivamente à dose parcelada em V4 e V8. A realização da adubação nitrogenada total de forma tardia, em V8, não gera efeito positivo no desenvolvimento da planta e na produtividade.

\footnotetext{
Abstract

The objective of this work was to verify the results of the division of nitrogen fertilization with urea in the culture of grain corn in stages V4 and V8. The experiment was carried out on the Ponte Alta farm, in the municipality of Silvânia-GO. The experimental design adopted was that of randomized blocks, with four treatments and four repetitions, being: T1 - zero; T2 - Urea 100\% V4; T3 - Urea 50\% V4 and 50\% V8; T4 - Urea 100\% V8. The nutritional demand of the crop was established according to the analysis of the soil being $261 \mathrm{~kg} \mathrm{ha}^{-1}$ of N. Plant height, stem diameter, green mass and the height of the ear insertion until full flowering were evaluated. Productivity at the end of the experiment. The results were subjected to analysis of variance, and when there were significant differences, identified by the $\mathrm{F}$ test $(\mathrm{P}<0.05)$, the Tukey means test was applied, using the Sisvar statistical program, version 5.6. The maize responded positively to nitrogen cover fertilization, in all studied characteristics. In the conditions of soil and climate of the analyzed area, the fertilization of nitrogen cover for the development of corn is more efficient when the application of $\mathrm{N}$ in cover is carried out in the vegetative stage V4, productively resembling the dose divided in V4 and V8. The late total nitrogen fertilization, in V8, does not have a positive effect on plant development and productivity.
} 


\section{INTRODUÇÃO}

O milho (Zea mays) é uma monocotiledônea da familia Poaceae, é um dos cereais mais cultivados no mundo, responsável pela alimentação animal e humana, devido as suas características nutricionais, e também pela produção de etanol, nos Estados Unidos. Os primeiros relatos são de que o milho tenha surgido próximo ao litoral do México a 7.500 anos atrás, e que a cultura tenha se difundido pela América do Sul e Central rapidamente (EMBRAPA, 2015).

Segundo a Conab (2019), no Brasil a safra total de 2018/2019 de produção de milho chegou a aproximadamente 100 milhões $t$, sendo que o milho de segunda safra apresentou estimativa de produção total com crescimento de $36,9 \%$ e previsão de produção recorde de 73,8 milhões t. A expectativa de exportação é de quase 35 milhões $t$, número recorde em relação as safras anteriores. De acordo com o FIESP (2020), o Brasil é o terceiro maior produtor mundial, ficando atrás apenas dos Estados Unidos e da China. A maior característica do milho, responsável por sua produção no mundo todo, é a alta adaptabilidade a diferentes condições climáticas (CUNHA et al., 2019).

A adubação nitrogenada é extremamente importante para o milho, já que se trata do nutriente absorvido em maior quantidade pela cultura, sendo o nitrogênio $(\mathrm{N})$ responsável pelas principais reações bioquímica nas plantas (CAIRES e MILLA, 2016). As fontes de $\mathrm{N}$ procuradas no mercado são aquelas capazes de aumentar a produtividade da cultura e que sejam economicamente viáveis, onde as perdas de aplicação sejam mínimas, portanto a ureia atende a esses pré-requisitos, sendo a fonte mais utilizada, porém os adubos nitrogenados mais comuns que contêm amônia e ureia são capazes de acidificar o solo, quando utilizados em doses elevadas (CAIRES et al., 2015).

Independente da fonte de $\mathrm{N}$ aplicada, este nutriente está sujeito a ser perdido por lixiviação, volatilização, erosão e desnitrificação e não ser absorvido pela planta, outra parte também pode ficar no solo na forma orgânica. A ureia deve ser incorporada ao solo, portanto não é a fonte recomendada para o plantio direto, já que podem ocorrer perdas por volatilização de amônia deste nutriente, principalmente no Brasil, devido às condições de altas temperaturas (MOTA et al., 2015).

O parcelamento da ureia pode ser favorável pensando em perdas por lixiviação, onde a quantidade de $\mathrm{N}$ disponível para lixiviar será menor, por outro lado, também será fornecida menor concentração de $\mathrm{N}$ que ficará disponível para a planta, mas se as condições climáticas forem favoráveis aumentará a eficiência do uso do nutriente pelas plantas de milho (MARTINS et al., 2014).

Em trabalho desenvolvido relacionado ao aumento da produtividade de grãos no parcelamento da adubação da ureia não foram constatados resultados significativos por ter realizado esta prática, porém houve aumento na produtividade de grãos quando as aplicações ocorreram em período chuvoso (MARTINS et al., 2014).

Considerou-se por Portugal et al. (2017) que a prática de aplicação única do $\mathrm{N}$ apenas na semeadura pode causar toxicidade sobre as plântulas, devido à grande concentração do nutriente aplicado de uma só vez, chamado de efeito tóxico do $\mathrm{N}$-fertilizante, podendo reduzir o estande, esse efeito sendo maior quando o nutriente utilizado é a ureia.

O objetivo deste trabalho foi verificar os resultados do parcelamento da adubação nitrogenada com ureia na cultura do milho grão no estágio V4 e V8.

\section{MATERIAL E MÉTODOS}

\section{Tipo de pesquisa e caracterização do local}

O experimento trata-se de pesquisa de campo realizada na fazenda Ponte Alta, no município de Silvânia, em Goiás (16041'26"S e 4847'23”W). Segundo Köppen, o clima característico da região é 
tropical com estação seca durante todo o ano, no inverno o clima é seco e no verão chuvoso. Em Silvânia a variação sazonal é extrema, a temperatura mínima média é de $15^{\circ} \mathrm{C}$ e máxima média de $31^{\circ} \mathrm{C}$. A pluviosidade média anual é $1.421 \mathrm{~mm}$. O solo do local é classificado como solo de textura média, de acordo com a análise de solo com o percentual de $68 \%$ de areia, $17 \%$ de argila e $15 \%$ de silte.

De acordo com os resultados e interpretação da análise de solo a saturação por bases (V\%) é alta, com resultado de $70,3 \%$, a capacidade de troca catiônica (CTC) é adequada com 8,4 $\mathrm{cmol}_{\mathrm{c}} \mathrm{dm}^{3}$, a acidez do solo foi considerada levemente ácido com resultado de $\mathrm{pH}$ 5,9. Os teores nutricionais apresentados por Cálcio (Ca), Magnésio (Mg) e matéria orgânica (MO) foram adequados, considerando 4,4; 1,4 $\mathrm{cmol}_{\mathrm{c}} \mathrm{dm}^{-3}$ e 2,3\%, respectivamente. Os teores de potássio $(K)$ obtiveram resultados de $43 \mathrm{mg} \mathrm{dm}^{-3}$, considerado médio e fósforo (P) de 54,3 $\mathrm{mg} \mathrm{dm}^{-3}$, considerado alto.

\section{Delineamento experimental}

$\mathrm{Na}$ execução do experimento foi utilizado o híbrido comercial FS 2B610 PW desenvolvido pela Forseed $\AA$, sementes de milho que garantem alto rendimento, sanidade foliar e sanidade de grãos, sendo o híbrido recomendado para a região.

O delineamento experimental adotado foi o de blocos ao acaso, com quatro tratamentos e quatro repetições, cada repetição com cinco linhas de plantas, espaçadas $0,45 \mathrm{~m}$. Os tratamentos foram assim divididos: T1 - Testemunha (sem adubação de cobertura); T2 - Ureia 100\% em V4; T3 - Ureia 50\% em V4 e 50\% em V8; T4 - Ureia 100\% em V8.

\section{Condução do experimento}

A área onde foi implantado o experimento havia sido cultivada anteriormente com a cultura da soja, sendo realizada a dessecação com Gramoxone ${ }^{\circledR}$ (paraquate) na dosagem de $2000 \mathrm{ml} \mathrm{ha}^{-1}$ para posterior plantio direto do milho e amostragem do solo para análise química (00-0,20 m). A semeadura e adubação de plantio foram realizadas no dia 04 de março de 2020, onde utilizou-se uma plantadeira de 11 linhas adotando o espaçamento entre as linhas de 0,45 m. Foram semeadas 2,8 sementes $\mathrm{m}^{-1}$. A adubação de plantio utilizada foi com $300 \mathrm{~kg} \mathrm{ha}^{-1}$ de 08-20-18 aplicados na área total.

A adubação de cobertura foi realizada no dia 06 de abril de 2020, onde foram realizadas as primeiras aplicações de ureia no estágio V4 do milho, adotando a regra de aplicação total da porção de ureia no tratamento 2 e 50\% no tratamento 3 (Figura 1). A ureia utilizada contém $46 \%$ N. De acordo com a análise do solo e a demanda nutricional da cultura foi estabelecido a dose de $\mathrm{N}$ em cobertura de $261 \mathrm{~kg} \mathrm{ha}^{-1}$. A segunda aplicação de ureia foi realizada no dia 25 de abril de 2020, no estágio V8 do milho, fazendo a aplicação de $50 \%$ no tratamento 3 e $100 \%$ no tratamento 4 .

Após 20 dias após a emergência (DAE) foram utilizados o inseticida Connect ${ }^{\circledR}$ (imidacloprido), na dosagem de $800 \mathrm{ml} \mathrm{ha}^{-1}$, os herbicidas Ultimato $\AA$ (atrazina) e Ridover ${ }^{\circledR}$ (glifosato), nas dosagens de 2,5 $\mathrm{kg} \mathrm{ha} \mathrm{h}^{-1}$ cada produto, a fim de controlar a incidência de pragas e plantas invasoras indesejadas. Aos $36 \mathrm{DAE}$ foi aplicado o inseticida Voraz ${ }^{\circledR}$ (metomil) na dosagem de $500 \mathrm{ml} \mathrm{ha}^{-1}$.

Foram utilizados como parâmetros de avaliações a altura da planta (m) (AP), e o diâmetro de colmo (DC) em mm. A altura de planta e diâmetro de colmo foram avaliados em três momentos, que foram após a $1^{\mathrm{a}}$ aplicação de ureia, após a $2^{\mathrm{a}}$ aplicação de ureia, no florescimento pleno (R2). Também foi avaliada a massa verde (g) (MV) e a altura da inserção da espiga (m), no florescimento pleno (R2), esta fase vai do $59^{\circ}$ ao $65^{\circ}$ dia, e a produtividade ( $\left.\mathrm{Pr}\right)$, no final do experimento.

Eliminando as plantas de bordadura para avaliação, a altura de planta (m) foi avaliada com o 
auxílio de uma trena, foi medida da base (solo) até o ápice da planta (inserção da última folha). O diâmetro de colmo (mm) foi avaliado com o auxílio de um paquímetro, medido acima do nível do solo no segundo nó do colmo. A massa verde foi estabelecida pela produção de matéria fresca da parte aérea. A altura da inserção da espiga (m) foi avaliada com o auxílio de uma trena, foi medida da base (solo) até o ponto de inserção da primeira espiga.

Aos 45 DAE e aos 60 DAE foram realizadas as avaliações de altura da planta e diâmetro do colmo, feitos após a primeira e segunda aplicação de ureia, respectivamente. A avaliação de massa verde e altura da inserção da espiga foram realizadas aos $85 \mathrm{DAE}$, onde também foi realizada a última avaliação de altura da planta e diâmetro do colmo.

A colheita foi realizada $142 \mathrm{DAE}$, no ponto de colheita (umidade do grão de 13\%) e foi realizada a avaliação de população final de plantas, onde contou-se o número de plantas e o número de espigas por planta em 4,0 m lineares; comprimento de espiga (base ao ápice) (cm); diâmetro de espiga (porção mediana da espiga) (mm); número de fileiras de grãos e número de grãos por fileira e massa de 1.000 grãos (pesagem de uma sub amostra de 100 grãos por parcela) (g).

A determinação da produtividade foi realizada contando o número de plantas em 4,0 m lineares e coleta-se três espigas aleatórias para determinação da média do peso dos grãos das três espigas. Sendo realizadas quatro repetições por parcela.

Os resultados foram submetidos à análise de variância (ANOVA), e quando ocorreram diferenças significativas, identificadas pelo teste $\mathrm{F}(\mathrm{P}<0,05)$, se aplicou o teste de médias de Tukey, utilizando-se programa estatístico Sisvar, versão 5.6 (FERREIRA, 2014).

\section{RESULTADOS E DISCUSSÃO}

Inicialmente foram avaliados os parâmetros fisiológicos, como diâmetro do colmo, altura de plantas, altura da primeira inserção da espiga e massa verde que foram influenciados pela aplicação do N. O momento da aplicação da adubação de cobertura nitrogenada é de suma importância pois o $\mathrm{N}$ está estritamente relacionado ao crescimento e ao rendimento da cultivar de milho. Tal fato corresponde principalmente por este nutriente se associar ao crescimento e desenvolvimento dos drenos reprodutivos e estar presente na molécula da clorofila, sendo indispensável para a manutenção da atividade fotossintética (MARTIN et al., 2011).

O diâmetro do colmo foi aferido em três momentos, aos 45, 60 e 85 DAE, para os três tratamentos (Figura 1). No tratamento com 100\% da adubação de cobertura realizada em V4, obteve-se uma maior espessura do colmo nas três aferições, se equiparando estatisticamente apenas aos 85 DAE no tratamento com $50 \%$ da dose de $\mathrm{N}$ em V4 e $50 \%$ em V8.

Se faz válido ressaltar que, em uma aplicação tardia, no estádio vegetativo V8, nos 45 e 85 DAE, o diâmetro de colmo se igualou estatisticamente ao tratamento sem adubação de cobertura, atestando a inviabilidade de adiar a adubação de cobertura nitrogenada, para o parâmetro diâmetro do colmo. Soratto et al. (2010) em um estudo de fontes alternativas e doses de nitrogênio no milho safrinha, observou que maiores diâmetros de colmos correlacionam positivamente com maiores produtividades de grãos, devido ao colmo funcionar como estrutura de reserva, fazendo a translocação de fotoassimilados do colmo para os grãos. 


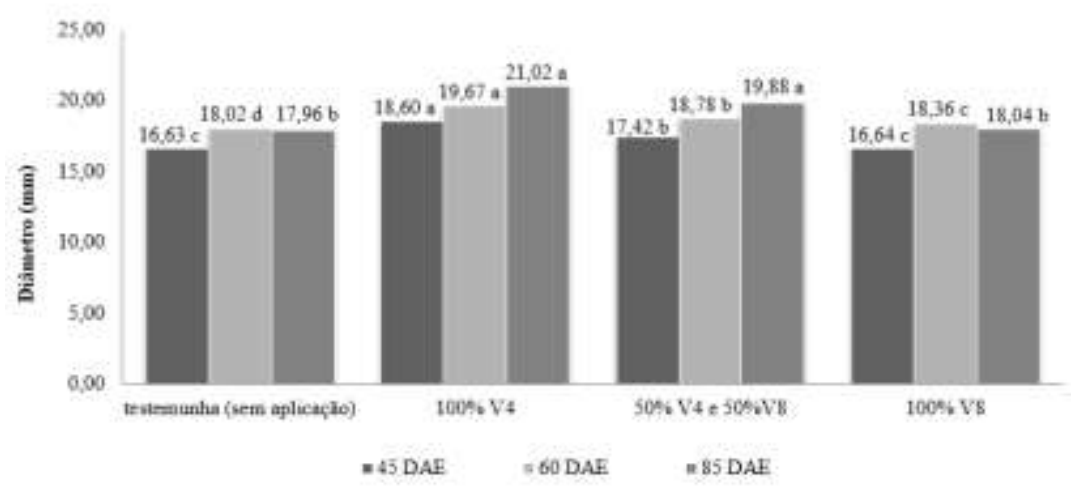

* médias seguidas da mesma letra na coluna não diferem entre si pelos teste de tukey a 5\% de probabilidade.

Figura 1. Diâmetro do colmo das plantas de milho, avaliado aos 45, 60 e 85 DAE em diferentes épocas de aplicação da adubação nitrogenada de cobertura, Silvânia, 2020.

Durante o experimento, a altura das plantas foi avaliada em três momentos após a emergência, conforme figura 2. As plantas que receberam adubação de cobertura durante V4 apresentaram a maior altura nos três momentos de aferição, estando o tratamento com adubação ocorrendo 100\% em V8 equiparado à testemunha sem adubação.
O resultado obtido está de acordo com Gross et al. (2005), que avaliando a altura de plantas em função das épocas de aplicação da cobertura nitrogenada, encontrou alturas mais elevadas em plantas com a adubação nitrogenada de cobertura em uma única aplicação ou dividida em duas, resultando em aumentos significativos na produtividade de milho sob plantio direto.

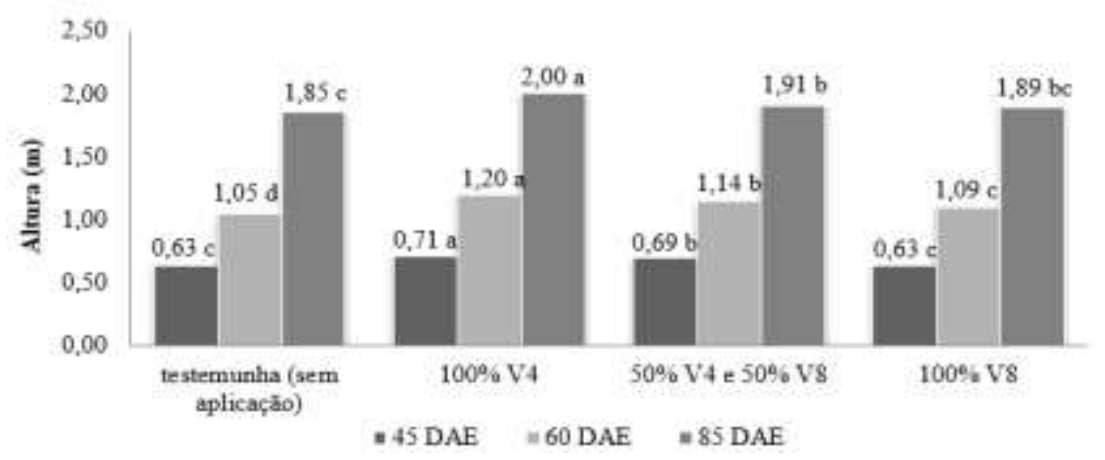

* médias seguidas da mesma letra na coluna não diferem entre si pelos teste de tukey a 5\% de probabilidade.

Figure 2. Altura de plantas de milho, avaliado aos 45, 60 e 85 DAE em diferentes épocas de aplicação da adubação nitrogenada de cobertura, Silvânia, 2020.

Foi aferida aos 85 DAE a altura da inserção de espiga, momento em que é possível realizar com precisão a medição para obtenção dos dados. É possível perceber que, para uma obtenção de altura maior para inserção de espiga é mais eficaz a não aplicação de cobertura nitrogenada que o parcelamento, visto que apenas o tratamento em que se dividiu a dose de ureia em cobertura, apresentou menor altura de inserção de espiga (Figura 3).

A altura da inserção da primeira espiga é um importante parâmetro a ser avaliado em cultivos de milho pois, segundo Kappes et al. (2011), em uma distância média entre o nível do solo e o ponto de inserção, resulta em um melhor equilíbrio da planta, 
reduzindo a ocorrência de possíveis acamamentos e dificuldade para realização da colheita. Os resultados obtidos concordam, de forma parcial, com Gross et al. (2005), que também obteve a maior média de altura de inserção espigas quando a adubação de cobertura foi realizada em uma única aplicação, ocorrendo após a semeadura, com suas menores médias em plantas submetidas à ausência de adubação de cobertura nitrogenada.

\section{Altura da Inserçào da Espiga}

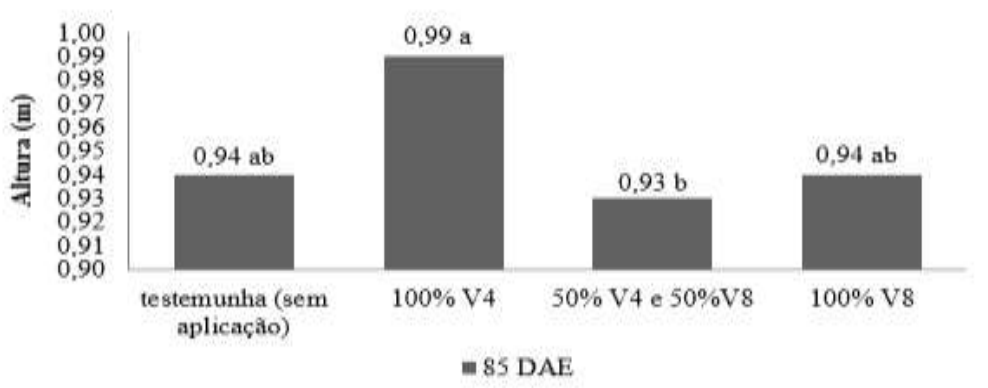

* médias seguidas da mesma letra na coluna não diferem entre si pelos teste de tukey a 5\% de probabilidade.

Figure 3. Altura da inserção da espiga de milho avaliado aos 85 DAE em diferentes épocas de aplicação da adubação nitrogenada de cobertura, Silvânia, 2020.

De acordo com Possamai et al. (2001), plantas mais altas e principalmente com altura de inserção de espigas mais altas, influenciam diretamente na colheita mecanizada, de forma a proporcionar vantagens relacionadas ao rendimento operacional em campo. Já para Souza; Yuyama (2015), plantas com inserção da espiga elevadas não são desejáveis, pois é um fator que pode influenciar na quebra do colmo e tombamento causado pelo vento, provocando redução na produtividade e dificuldade de colheita.

Resultados estatísticos significativos também foram positivos na variável massa fresca (MF) (Figura 4), sendo verificadas a massa fresca das folhas (MFF), a massa fresca do colmo (MFC) e a massa fresca da inflorescência (MFINFLOR). Quando realizada a adubação de cobertura nitrogenada em V4, a massa fresca, para os três parâmetros, é maior, sendo seguida pelos resultados obtidos ao parcelar em V4 e V8. Novamente observa-se em um parâmetro fisiológico que a aplicação tardia da adubação de cobertura nitrogenada à base de ureia agrícola, em V8, é ineficiente, se equiparando às plantas não adubadas (testemunha).
$\mathrm{O} \mathrm{N}$ além de se associar ao crescimento vegetativo, participa do processo de fabricação de fotoassimilados, fazendo parte das moléculas de clorofila, aminoácidos, DNA, citocromos e de todas as enzimas e coenzima, além de proporciona ganho de peso da espiga e elevar o percentual de óleos (FANCELLI; DOURADO NETO, 2008). Os parâmetros produtivos do milho também são altamente influenciados pela adubação nitrogenada de cobertura. O N é o nutriente de maior exigência pela cultura por desempenhar importante papel no acúmulo de proteína e na produtividade de grãos (PAVINATO et al., 2008).

$\mathrm{Na}$ tabela 1, é possível verificar que nos parâmetros CE, DE e GF, o tratamento com 100\% da dose em V4 apresentou os melhores resultados, com a aplicação de parcelada V4 e V8, se equiparando estatisticamente nestes parâmetros. No parâmetro MMG, o tratamento parcelado em V4 e V8, apresentou maior desempenho. Para a MMG, aplicar a adubação nitrogenada de cobertura em V8 se equipara à não adubação de cobertura, sendo inviável. 
O NF indicou que independente do momento da aplicação da adubação nitrogenada de cobertura é sendo superior à não adubação. Tal resultado obtido sinaliza que o número de fileiras é um parâmetro estabelecido pelo genótipo, quando ocorre $\mathrm{N}$ disponível no solo de forma suficiente.

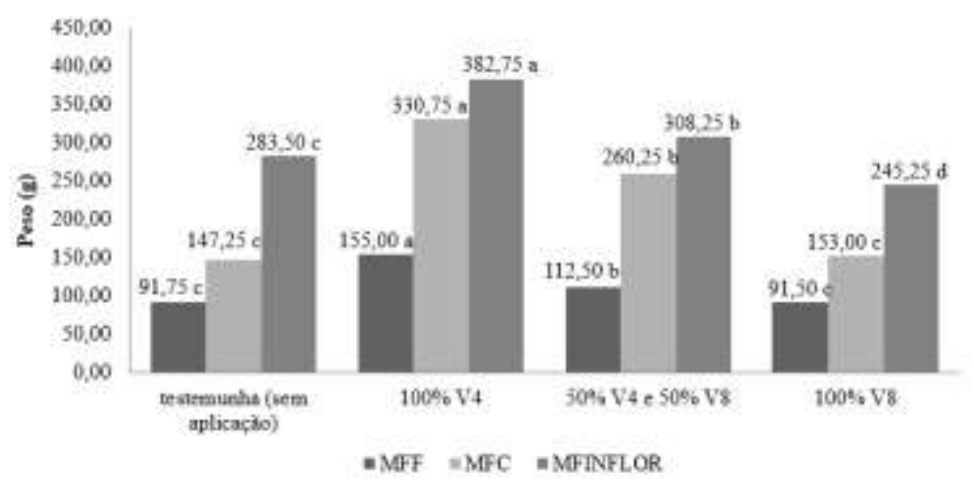

* médias seguidas da mesma letra na coluna não diferem entre si pelos teste de tukey a 5\% de probabilidade.

Figure 4. Massa fresca de folhas (MFF), colmo (MFC) e inflorescência (MFINFLOR) de milho avaliado aos 85 DAE em diferentes épocas de aplicação da adubação nitrogenada de cobertura, Silvânia, 2020.

Tabela 1. Comprimento de espiga (CE), diâmetro de espiga (DE), número de fileiras por espiga (NF), número de grãos por fileira (GF), massa de mil grãos (MMG), número de espigas a cada 10 metros (NE10m), número de grãos por espiga, peso médio da espiga (PME) e produtividade (PROD) em kg ha-1 e sacas ha-1 $\mathrm{de}^{-1}$ ilho em diferentes épocas de aplicação da adubação nitrogenada de cobertura, Silvânia, 2020.

\begin{tabular}{|c|c|c|c|c|c|c|c|c|c|c|}
\hline \multirow{2}{*}{ Tratamentos } & \multicolumn{2}{|c|}{$\mathrm{CE}$} & \multicolumn{2}{|l|}{$\mathrm{DE}$} & \multicolumn{2}{|l|}{$\mathrm{NF}$} & \multicolumn{2}{|l|}{ GF } & \multicolumn{2}{|c|}{ MMG } \\
\hline & \multicolumn{2}{|c|}{$\mathrm{cm}$} & \multicolumn{2}{|l|}{$\mathrm{mm}$} & \multicolumn{2}{|l|}{-} & \multicolumn{2}{|l|}{-} & \multicolumn{2}{|l|}{$g$} \\
\hline Testemunha (sem aplicação) & 15,23 & $\mathrm{c}$ & 46,18 & $\mathrm{~b}$ & 18,00 & $\mathrm{~b}$ & 25,16 & $\mathrm{c}$ & 270,16 & bc \\
\hline $100 \% \mathrm{~V} 4$ & 18,66 & $\mathrm{a}$ & 50,60 & $\mathrm{a}$ & 19,67 & $\mathrm{a}$ & 33,91 & a & 285,16 & $\mathrm{~b}$ \\
\hline $50 \% \mathrm{~V} 4$ e $50 \% \mathrm{~V} 8$ & 18,00 & $a b$ & 49,82 & $\mathrm{a}$ & 18,33 & $\mathrm{ab}$ & 33,00 & $\mathrm{ab}$ & 308,50 & $\mathrm{a}$ \\
\hline $100 \% \mathrm{~V} 8$ & 17,55 & $\mathrm{~b}$ & 47,76 & $\mathrm{~b}$ & 19,50 & $\mathrm{a}$ & 31,50 & $\mathrm{~b}$ & 264,33 & $\mathrm{c}$ \\
\hline Teste F & 0,000 & $* *$ & 0,000 & $* *$ & 0,005 & $* *$ & 0,000 & $* *$ & 0,000 & $* *$ \\
\hline $\mathrm{CV}(\%)$ & 8,12 & & 5,08 & & 10,11 & & 9,84 & & 7,93 & \\
\hline \multirow{2}{*}{ Tratamentos } & \multicolumn{2}{|c|}{ NE10m } & \multicolumn{2}{|c|}{ NGE } & \multicolumn{2}{|c|}{ PME } & \multicolumn{2}{|l|}{ PROD } & \multicolumn{2}{|c|}{ PROD } \\
\hline & \multicolumn{2}{|l|}{-} & \multicolumn{2}{|l|}{-} & & & \multicolumn{2}{|c|}{$\mathrm{Kg} \mathrm{ha}^{-1}$} & \multicolumn{2}{|c|}{ sc ha-1 } \\
\hline Testemunha (sem aplicação) & 27,41 & $\mathrm{~b}$ & 453,67 & $\mathrm{~b}$ & 122,74 & $\mathrm{c}$ & $5.138,53$ & c & 85,64 & $\mathrm{c}$ \\
\hline $100 \% \mathrm{~V} 4$ & 30,58 & $\mathrm{a}$ & 672,20 & $\mathrm{a}$ & 191,67 & $\mathrm{a}$ & $9.041,71$ & a & 150,70 & $\mathrm{a}$ \\
\hline $50 \% \mathrm{~V} 4$ e $50 \% \mathrm{~V} 8$ & 30,58 & $\mathrm{a}$ & 606,25 & a & 186,52 & $\mathrm{a}$ & $8.793,74$ & $\mathrm{a}$ & 146,56 & $\mathrm{a}$ \\
\hline $100 \% \mathrm{~V} 8$ & 26,67 & $\mathrm{~b}$ & 613,25 & $\mathrm{a}$ & 162,54 & $\mathrm{~b}$ & $6.681,68$ & $\mathrm{~b}$ & 111,36 & $\mathrm{~b}$ \\
\hline Teste F & 0,000 & $* *$ & 0,000 & $* *$ & 0,000 & $* *$ & 0,000 & $* *$ & 0,000 & $* *$ \\
\hline $\mathrm{CV}(\%)$ & 5,10 & & 17,27 & & 18,84 & & 19,97 & & 19,97 & \\
\hline
\end{tabular}

*médias seguidas da mesma letra na coluna não diferem entre si pelo teste Tukey a $5 \%$ de probabilidade.

Para a NE10m, PME e produtividade, a aplicação da adubação nitrogenada de cobertura total em V4 ou parcelada, não apresentaram diferenças estatísticas, sendo a melhor maneira de realizar a aplicação do $\mathrm{N}$ em cobertura para o aumento da produtividade. Para o NGE a presença da adubação nitrogenada foi suficiente para que a espiga apresentasse o seu potencial produtivo uniformemente de uma forma superior que a ausência de adubação de cobertura. 
De forma geral, os melhores resultados foram obtidos com a aplicação da adubação de cobertura nitrogenada à base de ureia no estádio V4. Resultados semelhantes foram obtidos no trabalho de Santos et al. (2010), onde a aplicação do N em V4 apresentou melhores resultados em comparação à aplicação precoce da adubação, seja 15 dias antes do plantio, ou total no momento da semeadura.

Quando a planta atinge estádio V4, deve ser realizado a adubação de cobertura nitrogenada, pois no estádio V8, não há reação da planta em relação ao $\mathrm{N}$ fornecido via cobertura. Uma adubação parcial em V4, com $50 \%$ da dosagem é capaz de garantir com que a planta não sofra decréscimos fisiológicos e produtivos, tendo maior eficiência que a adubação total em V8. Porém visando um melhor rendimento operacional, em muitas regiões produtoras de milho safrinha tem sido comum uma única aplicação de $\mathrm{N}$ em adubação de cobertura, realizada quando as plantas se encontram em estádios fenológicos entre V4 e V7 (KAPPES et al., 2019).

De acordo com Duarte; Cantarella (2014), em grande parte dos estudos, não se verificou vantagem em parcelar a adubação de cobertura nitrogenada para aplicação de uma parte próximo do estádio de florescimento, especialmente em solos argilosos, pois o sistema radicular se apresenta melhor desenvolvido, permitindo a absorção de $\mathrm{N}$ em grande volume de solo, que pode ser oriundo do fertilizante ou não, assim não sendo eficaz em uma visão operacional.

O melhor resultado apresentado em 100\% da cobertura nitrogenada em V4 pode ser explicado, pois, para que a adubação nitrogenada funcione de forma mais efetiva, deve-se estabelecer o período em que o nutriente é requerido em maior quantidade pela cultura, desta forma, suprindo as carências à medida que planta se desenvolve, estando tais exigências ocorrendo no estágio V4, onde é definido pela planta o potencial produtivo (KAPPES et al., 2019).

\section{CONCLUSÃO}

O milho FS 2B610 PW respondeu positivamente à adubação nitrogenada de cobertura, em todas as características estudadas.

Nas condições de solo e clima de Silvânia, GO, a adubação de cobertura nitrogenada para o desenvolvimento do milho é mais eficiente quanto a aplicação do $\mathrm{N}$ em cobertura é realizada no estádio vegetativo $\mathrm{V} 4$, se assemelhando produtivamente à dose parcelada em V4 e V8.

A realização da adubação nitrogenada total de forma tardia, em V8, não gera efeito positivo no desenvolvimento da planta e na produtividade.

\section{REFERÊNCIAS}

CAIRES, E. F., HALISKI, A., BINI, A. R. E SCHARR, D. A. Calagem superficial e adubação nitrogenada para produção de grãos sob plantio direto no Brasil. European Journal of Agronomy, v. 66, p.41-53, 2015.

CAIRES, E. F.; MILLA, R. Adubação nitrogenada em cobertura para o cultivo de milho com alto potencial produtivo em sistema de plantio direto de longa duração. Bragantia, v. 75 , n. 1, p. $87-$ 95, 2016.

CONAB. Boletim Grãos dezembro de 2019. 2019.

CUNHA, B. A.; NEGREIROS, M. M. de; ALVES, K. A.; TORRES, J. P. Influência da época de semeadura na severidade de doenças foliares e na produtividade do milho safrinha. Summa Phytopathologica, v. 45, n. 4, p.424-427, 2019.

DUARTE, A.P.; CANTARELLA, H. Milho: oferta harmônica. Revista Cultivar, Pelotas, n.177, p.6-8, 2014.

EMBRAPA. Sistemas de Produção: Cultivo do milho. $9^{\text {a }}$ ed. Nov. 2015.

FANCELLI, A. L.; D. DOURADO NETO. Produção de milho. Guaíba: 2.ed., Agropecuária. 2008. 360p. 
FERREIRA, D. F. Sisvar: a guide for its bootstrap procedures in multiple comparisons. Ciência e Agrotec., Lavras, v. 38, n. 2, p. 109-112, 2014. https://doi.org/10.1590/S141370542014000200001 .

GROSS, M. R., PINHO, R. V., \& BRITO, A. D. (2005). Adubação nitrogenada, densidade de semeadura e espaçamento entre fileiras na cultura do milho em sistema plantio direto. 2005. Tese de Doutorado. Universidade Federal de Lavras.

KAPPES, C. ANDRADE, J. A. C, AFR, O.; OLIVEIRA, A. C.; ARF, M. V.; FERREIRA, J. P. Desempenho de híbridos de milho em diferentes arranjos espaciais de planta. Bragantia, Campinas-SP, v. 70, n. 2, 2011, 333$334 \mathrm{p}$

KAPPES, C.; ABRANTES, F. L.; ARF, M. V; CRUZ, F. A. B. Complementação tardia de nitrogênio em cobertura do milho safrinha sob semeadura direta. Milho Safrinha. XV Seminário Nacional. Jataí, Goiás. 2019.

MARTIN, T.N.; PAVINATO, P.S.; SILVA, M.R.; ORTIZ, S.; BERTONCELI. Fluxo de nutrientes em ecossistemas de produção de forragens conservadas. In: Anais do IV In: Anais do Simpósio sobre produção e utilização de forragens conservadas, Maringá. 2011. p.319. p.173-219.

MARTINS, I. S.; CAZETTA, J. O.; FUKUDA, A. J. F. Condições, modos de aplicação e doses de ureia revestida por polímeros na cultura do milho. Pesquisa Agropecuária Tropical, v. 44, n. 3, p.271-279, set. 2014.

MOTA, M. R., SANGOI, L., SCHENATTO, D. E., GIORDANI, W., BONIATTI, C. M., \& DALL'IGNA, L. Fontes estabilizadas de nitrogênio como alternativa para aumentar o rendimento de grãos e a eficiência de uso do nitrogênio pelo milho. Revista Brasileira de Ciência do Solo, v. 39, n. 2, p. 512-522, 2015.

PAVINATO, P. S.; CERETTA, C. A.; GIROT'TO, E.; MOREIRA, I. C. L. Nitrogênio e potássio em milho irrigado: análise técnica e econômica da fertilização. Ciência Rural, v.38, p.358-364, 2008.

PORTUGAL, J. R.; ARF, O.; PERES, A. R.; GITTI, D. C.; FERNANDA, N.; GARCIA, S. Coberturas vegetais, doses de nitrogênio e inoculação com Azospirillum brasilense em milho no Cerrado. Revista Ciência Agronômica, v. 48, n. 4, p.641-649, 2017.

POSSAMAI, J., SOUZA, C., \& Galvão, J. C. C. Sistemas de preparo do solo para o cultivo do milho safrinha. Bragantia, v. 60, n. 2, p. 79-82, 2001.

SANTOS, M. M., GALVÃO, J. C. C., SILVA, I. R., MIRANDA, G. V., \& FINGER, F. L. Épocas de aplicação de nitrogênio em cobertura na cultura do milho em plantio direto, e alocação do nitrogênio (15N) na planta. Revista brasileira de ciência do solo, v. 34, n. 4, p. 1185-1194, 2010 .

SORAT'TO, R. P., PEREIRA, M., MINGOT'TI DA COSTA, T. A., \& LAMPERT, V. D. N. Fontes alternativas e doses de nitrogênio no milho safrinha em sucessão à soja. Revista Ciência Agronômica, p. 511-518, 2010.

SOUSA, A. L. B.; YUYAMA, K.; Desempenho agronômico de cultivares de milho com adubação nitrogenada em cobertura no cerrado de Humaitá. Igápo-AM - Revista de educação, ciência e tecnologia do ifam. v. 9, n. 2, 2015. 